\title{
Editorial: Human-Induced Excitations and Vibrations Serviceability of Civil Engineering Structures
}

\author{
Onur Avci ${ }^{1 *}$ and F. Necati Catbas ${ }^{2}$ \\ ${ }^{1}$ Department of Civil, Construction, and Environmental Engineering, lowa State University, Ames, IA, United States, ${ }^{2}$ Department \\ of Civil, Environmental, and Construction Engineering, University of Central Florida, Orlando, FL, United States
}

Keywords: Floor vibrations serviceability, floor vibrations, human induced excitations, vibrations control, structural engineering, structural dynamics

\section{Editorial on the Research Topic}

\section{Human-Induced Excitations and Vibrations Serviceability of Civil Engineering Structures}

This research topic focuses on the latest developments in human-induced excitations and vibrations serviceability of civil structures (Jones et al., 2011; Younis et al., 2017; Živanović et al., 2005). In the last couple of decades, the use of high-strength construction materials enabled the design and construction of longer structural spans which resulted in slender architectures (Abdeljaber et al., 2016; Barrett et al., 2006; Muhammad et al., 2018; Sachse et al., 2004). In addition to this, the floor loading is becoming "paperless" and more lightly damped which makes them more susceptible to unwanted vibrations (Avci et al., 2019; Catbas et al.; Ngoan et al., 2018; Racic et al., 2009). Human activities such as walking, running, jumping, dancing, aerobics, etc. cause these unwanted vibrations on civil structures for which humans are both the excitation source and the sensor (Racic et al., 2010; Racic and Pavic 2009; Shahabpoor et al., 2017). This research topic includes four papers that shed light on challenges in this area.

The publication by Drira et al., entitled "Uncertainties in Structural Behavior for Model-Based Occupant Localization Using Floor Vibrations," highlights the importance of non-intrusive sensing approaches for tracking occupants inside buildings. In this paper, the authors describe an extensive analysis of vibrations induced by a range of occupants. As a first step, the need for a structuralbehavior model for occupant localization is evaluated using two full-scale case studies. As a second step, measured data are interpreted using physics-based models and information related to uncertainties from multiple sources. The authors carried out model-based occupant localization using Error-domain model falsification (EDMF) and residual minimization (RM) on a full-scale case study. They conclude that, by explicitly accounting for the presence of uncertainties and the influence of structural behavior, EDMF, unlike RM, accurately reveals possible occupant locations on floor slabs.

The study by Bassoli and Vincenzi, entitled "Parameter Calibration of a Social Force Model for the Crowd-Induced Vibrations of Footbridges", propose a parameter calibration of the Helbing's social force model performed adopting the response surface methodology, for the simulation of unidirectional pedestrian flows on footbridges. The authors calibrated the parameters of the social force model to represent the fundamental relation between mean walking speed and density of the pedestrian crowd. In the crowd simulation, each pedestrian crossing the footbridge were modeled as a vertical load with time varying trajectory and velocity estimated from the calibrated social force model. The simulation results are compared to those obtained from a multiplication factor approach proposed in literature and showed good agreement. 
In the paper by Díaz et al., entitled "Interaction Phenomena to Be Accounted for Human-Induced Vibration Control of Lightweight Structures," the authors present a frequencydomain framework to be used for designers in the integration of vibration control devices in lightweight pedestrian structures susceptible to suffer from interaction phenomena. The authors discuss how the structure to be controlled is affected when human-structure interaction is presented for deterministic and stochastic conditions; the closed-loop transfer function of the controlled structure including a passive inertial mass damper; and the closed-loop transfer function of the controlled structure including an active inertial mass damper.

The study by Royvaran et al., entitled "Effect of Non-Structural Components on the Dynamic Response of Steel-Framed Floors: Tests Before and After Component Installations," focuses on the effect of partition walls and non-structural elements on the dynamic response of floors. The authors emphasize the fact that the best way to shed light on the effect of non-structural components is to test additional floors before and after the

\section{REFERENCES}

Abdeljaber, O., Younis, A., Avci, O., Catbas, N., Gul, M., Celik, O., et al. (2016). "Dynamic Testing of a Laboratory Stadium Structure." Geotechnical and Structural Engineering Congress 2016 - Proceedings of the Joint Geotechnical and Structural Engineering Congress, Phoenix, AZ, February 14-17, 2016.. doi:10.1061/9780784479742.147

Avci, O., Bhargava, A., Nikitas, N., and Inman, D. J. (2019). Vibration Annoyance Assessment of Train Induced Excitations from Tunnels Embedded in Rock. Sci. Total Environ.. doi:10. 1016/j.scitotenv.2019.134528

Barrett, A. R., Avci, O., Setareh, M., and Murray, T. M. (2006). Observations from Vibration Testing of In-Situ Structures St. Louis, Missouri, United States: Structures Congress

Jones, C. A., Reynolds, P., and Pavic, A. (2011). Vibration Serviceability of Stadia Structures Subjected to Dynamic Crowd Loads: A Literature Review. J. Sound Vibration. doi:10.1016/j.jsv.2010.10.032

Muhammad, Z., Reynolds, P., Avci, O., and Hussein, M. (2018). Review of Pedestrian Load Models for Vibration Serviceability Assessment of Floor Structures. Vibration.

Ngoan, T. D., Gul, M., Abdeljaber, O., and Avci, O. (2018). Novel Framework for Vibration Serviceability Assessment of Stadium Grandstands Considering Durations of Vibrations. J. Struct. Eng. doi:10.1061/(asce)st.1943-541x.0001941

Racic, V., Brownjohn, J. M. W., and Pavic, A. (2010). Reproduction and Application of Human Bouncing and Jumping Forces from Visual Marker Data. J. Sound Vibration. doi:10.1016/j.jsv.2010.02.021

Racic, V., Pavic, A., and Brownjohn, J. M. W. (2009). Experimental Identification and Analytical Modelling of Human Walking Forces: Literature Review. J. Sound Vibration. doi:10.1016/j.jsv.2009.04.020

Racic, V., and Pavic, A. (2009). Mathematical Model to Generate Asymmetric Pulses Due to Human Jumping. J. Eng. Mech. 135 (10). doi:10.1061/(asce)em. 1943-7889.0000044 installation of non-structural elements and then compare the dynamic properties. For this purpose, they conducted vibration testing on a building floor under construction at various stages of fit-out to quantify the effects of various non-structural elements on the vibration response. The frequency response functions were compared, and the installation of non-structural components was found to influence the dynamic response of the tested floor. It is indicated that, combined with the other test data in the literature, the results of this study might lead to more effective modeling techniques and provide guidance as to their inclusion into analytical models.

\section{AUTHOR CONTRIBUTIONS}

$\mathrm{OA}$ and FC actively worked in a collaborative effort. OA contacted the potential authors suitable for this research topic. FC contacted the potential authors for this research topic as well. Both OA and FC served as editors for the submitted manuscripts.

Sachse, R., Pavic, A., and Reynolds, P. (2004). Parametric Study of Modal Properties of Damped Two-Degree-Of-freedom Crowd-Structure Dynamic Systems. J. Sound Vibration. doi:10.1016/j.jsv.2003.08.052

Shahabpoor, E., Pavic, A., Racic, V., and Zivanovic, S. (2017). Effect of Group Walking Traffic on Dynamic Properties of Pedestrian Structures. J. Sound Vibration. doi:10.1016/j.jsv.2016.10.017

Younis, A., Avci, O., Hussein, M., Davis, B., and Reynolds, P. (2017). Dynamic Forces Induced by a Single Pedestrian: A Literature Review. Appl. Mech. Rev. 69 (2), 020802. doi:10.1115/1.4036327

Živanović, S., Pavic, A., and Reynolds, P. (2005). Vibration Serviceability of Footbridges under Human-Induced Excitation: A Literature Review. J. Sound Vibration.

Conflict of Interest: The authors declare that the research was conducted in the absence of any commercial or financial relationships that could be construed as a potential conflict of interest.

Publisher's Note: All claims expressed in this article are solely those of the authors and do not necessarily represent those of their affiliated organizations, or those of the publisher, the editors and the reviewers. Any product that may be evaluated in this article, or claim that may be made by its manufacturer, is not guaranteed or endorsed by the publisher.

Copyright (c) 2022 Avci and Catbas. This is an open-access article distributed under the terms of the Creative Commons Attribution License (CC BY). The use, distribution or reproduction in other forums is permitted, provided the original author(s) and the copyright owner(s) are credited and that the original publication in this journal is cited, in accordance with accepted academic practice. No use, distribution or reproduction is permitted which does not comply with these terms. 